\title{
Neutrophil-to-Lymphocyte Ratio at Hospital Admission as a Novel Predictor of Early Growth of Intraparenchymal Haemorrhage in Patients With Traumatic Brain Injury
}

\author{
Dongzhou Zhuang \\ First Affiliated Hospital of Shantou University \\ Jiangtao Sheng \\ Shantou University Medical College

\section{Guoyi Peng} \\ The First Affiliated Hospital of Shantou University Medical College \\ Tian Li \\ Shantou University Medical College

\section{Shirong Cai} \\ The First Affiliated Hospital of Shantou University Medical College

\section{Faxiu Ding} \\ The First Affiliated Hospital of Shantou University Medical College

\section{Lianjie Li} \\ Fuzhou General Hospital of Xiamen University

\section{Mindong Huang} \\ Jieyang people's Hospital

\section{Fei Tian} \\ Second Affiliated Hospital of Shantou University Medical College

\section{Kangsheng Li} \\ Shantou University Medical College

\section{Shousen Wang} \\ Fuzhou General Hospital of Xiamen University \\ weiqiang chen ( $\square$ wqchen@stu.edu.cn ) \\ First Affiliated Hospital of Shantou Medical University
}

\section{Research}

Keywords: Neutrophil-to-lymphocyte ratio, Haematoma, traumatic intraparenchymal haemorrhage, Computed tomography, Traumatic brain injury

Posted Date: November 4th, 2020

DOI: https://doi.org/10.21203/rs.3.rs-100356/v1 
License: (a) (1) This work is licensed under a Creative Commons Attribution 4.0 International License. Read Full License 


\section{Abstract}

Background

This study aimed to explore the association between the neutrophil-to-lymphocyte ratio (NLR) and early growth of traumatic intraparenchymal haemorrhage $(\mathrm{t} I \mathrm{CH})$ in patients with traumatic brain injury.

Methods

A multicentre, observational cohort study was conducted at four hospitals and included patients with cerebral contusion undergoing baseline computed tomography (CT) for haematoma volume analysis within 6 hours after primary injury and who had follow-up visits within 48 hours. Routine blood tests were performed upon admission and analysed with early $\mathrm{PIH}$. Logistic regression and receiver operating characteristic (ROC) analysis was used to explore the predictive value of the NLR for haematoma expansion.

Results

The final analysis included 1003 patients in the retrospective development and validation cohorts. In the retrospective development cohort, the NLR were higher in the PIH group than in the non-PIH group $(P<0.0001)$. Multivariate logistic regression analysis revealed that a higher NLR was independently associated with $\mathrm{PIH}$ $(P<0.0001)$. ROC curve analysis showed that the NLR had a sensitive ability for predicting PIH (AUC, 0.91 [95\% Cl, $0.88-0.94])$. In the validation study, the NLR had a similar ability to predict PIH.

Conclusion

The NLR can be used to easily assess the growth of $\mathrm{tICH}$ and calculated using routine laboratory tests. A high NLR is independently predictive of early growth of $\mathrm{tICH}$ and may aid in risk stratification of patients with $\mathrm{tICH}$ on admission.

\section{Background}

Despite extensive study and improvements in critical care, outcomes after early intraparenchymal haemorrhage growth in patients with traumatic brain injury $(\mathrm{tICH})$ continue to be poor and difficult to predict.

In developed countries tICH remains the commonest cause of death among individuals younger than 40 years, and in developing countries, the incidence and societal costs of $\mathrm{tICH}$ are rising. It is well demonstrated that $\mathrm{tICH}$ includes numerous types of insults to the brain, one of the most serious being haemorrhagic cerebral contusion. Occurring in more than $40 \%$ of severe $\mathrm{tICH}$ cases, intraparenchymal haemorrhage plays an important role in conferring a poor prognosis. In particular, secondary damage resulting from progressive intraparenchymal haemorrhage $(\mathrm{PIH})$, which is defined as haematoma growth $>33 \%$ or $5 \mathrm{~cm}^{3}$ on subsequent computed tomographic (CT) scanning, has been reported in $38 \%-59 \%$ of patients with $\mathrm{tICH}$ and is an independent predictor of a poor functional outcome[1,2].

There is a large body of evidence suggesting that neuroinflammation is an important injury mechanism that contributes to ongoing neurodegeneration and neurological impairments associated with $\mathrm{tICH}$. Posttraumatic neuroinflammation is characterized by glial cell activation, leukocyte recruitment, and upregulation of inflammatory mediators. Although many studies have focused on the detrimental effects of neuroinflammation on 
the injured brain, there are clear beneficial effects that can be achieved if neuroinflammation is identified as a novel predictor for haemorrhage growth that can be is crucial for early therapeutic intervention.

Accumulative evidence has shown that many risk factors, such as baseline haematoma volume, early baseline computed tomography (CT) time, Glasgow Coma Scale (GCS), subarachnoid haemorrhage (SAH), subdural haemorrhage $(\mathrm{SDH})$, and coagulopathy, are associated with haematoma expansion. The neutrophil-to-leukocyte ratio (NLR), which is a significant indicator for predicting the inflammatory status of patients, has been shown to be a predictor of prognosis among patients with conditions involving the brain including glial tumours[3,4], ischaemic stroke[5], haemorrhagic stroke[6], and convulsive status epilepticus[7]. Moreover, we have previously shown that in patients with severe $\mathrm{IICH}$, the NLR can predict long-term outcomes[8]. However, there has been a lack of research on whether the NLR can predict early haematoma growth in patients with tICH. Therefore, the aim of this study was to assess the value of the NLR for predicting intraparenchymal haematoma growth in patients with $\mathrm{tICH}$.

\section{Materials And Methods}

\section{Patient population}

Consecutive patients with primary traumatic cerebral contusion who were admitted to 1 of 4 hospitals (First and Second Affiliated Hospitals of Shantou University Medical College, Jieyang People's Hospital and Fuzhou General Hospital of Xiamen University) between January 1, 2012, and April 31, 2019, were enrolled in this cohort study. Patients admitted between 2012 and 2015 were assigned to the retrospective development cohort, and those admitted between 2016 and 2019 were assigned to the prospective validation cohort. The inclusion criteria were as follows: (1) at least 18 years; (2) documentation of a baseline CT scan within 6 hours after brain injury and a follow-up CT within 48 hours after the initial CT; (3) documentation of an initial blood test within 24 hours; and (4) at least one confirmed PIH on the initial CT. The exclusion criteria were as follows: (1) surgery performed before the follow-up CT scan, (2) previous head trauma, (3) previous coagulopathy, or (4) use of antiplatelet or anticoagulant medication.

\section{Data collection}

All patients underwent a brain CT scan immediately after admission. The follow-up CT scan was routinely performed within 48 hours of the initial CT or when the patient's condition deteriorated. The haematoma volume was calculated by CT. Inter-reader variability was determined by having the CT image analysed by 2 independent neuroradiologists who were blinded to the treatment (the number of 5-mm slices containing haemorrhage was multiplied by 0.5)[9]. Haematoma expansion was defined as a $33 \%$ or more than $5-\mathrm{mL}$ increase in volume on the follow-up CT scan compared with that on the baseline CT, as previously defined[10,11] (Figure 1).

Venous blood samples were drawn by venous puncture on admission and stored in tubes containing various anticoagulants for routine blood tests. Routine blood examinations, including examinations of the leukocyte count (reference range, 3.5-9.5 10\% /L), neutrophil count (reference range, 1.8-6.4 10\% $/ \mathrm{L}$ ), lymphocyte count (reference range, $1.1-3.210^{9} / \mathrm{L}$ ) and mononuclear cell count (reference range, $0.1-0.610^{9} / \mathrm{L}$ ), were measured for all patients by the routine laboratory assays used at the participating hospitals. The NLR is the number of neutrophils divided by the number of lymphocytes.

\section{Statistical analysis}


Data were analysed using SPSS 22 (SPSS Inc., Chicago, Illinois) and MedCalc 18.2.1 (MedCalc Software, Mariakerke, Belgium). Continuous variables are expressed as the means \pm standard deviations, and categorical variables are expressed as counts (percentages). Continuous variables were compared by a two-sample t-test, whereas categorical data were analysed using the Pearson $\chi 2$ test or Fisher's exact test. A univariate analysis with a non-linear correlation (cubic spline functions) was used to evaluate the shape of the relationship between the continuous variables and outcomes. A multivariate logistic regression model analysis was used to identify the associations between PIH expansion or the indices of inflammation, including the leukocyte count, neutrophil count, lymphocyte count, mononuclear cell count and NLR, and their corresponding risk factors (selection: forward [method $=$ Wald]). The results are presented as odds ratios (ORs) and 95\% confidence intervals (Cls). Receiver operating characteristic (ROC) curve analysis was performed to assess the predictive performance for PIH expansion by the NLR values on admission. Using the ROC curve, the cut-off values were estimated, and the corresponding sensitivities and specificities were calculated based on the area under the curve (AUC) of the ROC curve. Statistical significance was set at $P<0.05$.

\section{Results}

\section{General information}

Based on the eligibility criteria, 412 of 1498 patients with primary traumatic parenchymal haemorrhage were included in the final development cohort, and 591 of 1516 patients were included in the final validation cohort (Table 1). The baseline clinical characteristics were comparable between the development and validation cohorts.

\section{Prediction of haematoma expansion}

In the univariate analysis, $\mathrm{SAH}, \mathrm{SDH}$, time to baseline $\mathrm{CT}$, baseline CT haematoma volume, coagulopathy, multiple haematomas (no less than 3 haematomas), lymphocyte count and NLR were associated with haematoma expansion in both cohorts (Table 2) and were entered into a multivariable logistic regression. Lymphocyte count, $\mathrm{SDH}$, multiple haematomas and the NLR remained significant in the multivariable analysis (Table 3 ).

The NLR was an independent predictor of haematoma expansion, and for the diagnostic performance for haematoma expansion, the NLR displayed a sensitivity of 0.81 and a specificity of 0.87 . The predictive performance of the single-factor model of the NLR (AUC, 0.91 [95\% Cl, 0.88-0.94]) was better than the predictive performance of a multifactor model that included baseline CT time, baseline haematoma volume, multiple haematomas, SDH and coagulopathy (AUC, 0.74 [95\% Cl, 0.68-0.79]; $P<0.001$ ) (Figure 2).

\section{Validation cohort}

Similar results were found in the validation cohort, with the NLR being a strong independent predictor of haematoma expansion in the multivariable model, showing a sensitivity of 0.85 and a specificity of 0.76 . The predictive performance of the NLR for haematoma expansion (AUC, 0.87 [95\% Cl, 0.84-0.89]) was higher than that of the multifactor model (AUC, 0.77 [95\% Cl, 0.73-0.81]; $P=0.001$ ) (Table 4, Figure 3).

\section{Operation group vs non-operation group}

Among all 505 patients with haematoma expansion, 166 required surgical intervention. Univariate analysis was performed to identify risk factors for surgical intervention. Statistically significant differences in the GCS score, 
mean arterial pressure (MAP), initial haematoma volume, SAH, SDH, epidural haematoma (EDH), encephalatrophy and NLR were found between those who needed surgical intervention and those who did not (Table 5). Multivariate logistic regression revealed that the GCS score $(\mathrm{OR}=0.929,95 \% \mathrm{Cl}, 0.873-0.988), \mathrm{MAP}(\mathrm{OR}=1.010,95 \% \mathrm{Cl}$, 1.001-1.020), initial haematoma volume $(\mathrm{OR}=1.064,95 \% \mathrm{Cl}, 1.035-1.093)$ and $\mathrm{NLR}(\mathrm{OR}=1.0256,95 \% \mathrm{Cl}$, 1.003-1.047) were risk factors for the requirement for surgical intervention (Table 6). The NLR values of the operation group and the non-operation group were significantly different $(P=0.004)$.

\section{Discussion}

The current study demonstrated that the values of the NLR on admission of the patients with PIH were significantly higher than those of the patients without PIH. Furthermore, in the multivariate logistic regression models of predictors of early growth of traumatic intracranial haematoma, the NLR on admission was a significant independent predictor of traumatic intracranial haematoma expansion. Importantly, the prognostic performance of the NLR for PIH was higher than that of in the multifactor model, substantiating the potential of the NLR as a new prognostic marker in $\mathrm{PIH}$. Interestingly, in patients with haematoma expansion, the NLR of the surgical group was significantly higher than that of the non-surgical group. Taken together, these findings raise the intriguing possibility that neuroinflammation plays a role in the pathophysiology of $\mathrm{PIH}$.

In a recent study, haematoma expansion occurred in approximately one-third of patients and was strongly associated with poor outcomes[12]. As a potentially modifiable determinant of $\mathrm{tICH}$ prognosis, haematoma expansion represents an appealing target for acute $\mathrm{tICH}$ treatment[13]. In recent years, novel predictors for early haematoma growth in patients with $\mathrm{tICH}$, including leukocyte count[14], coagulopathy[15,16] and the shape of the haematoma on a head CT, have been developed[17]. The presence of SDH has been identified as a promising imaging predictor for haematoma growth. Interestingly, our study shows that SDH may be closely related to haematoma expansion when haematoma and SDH appear together on a head CT. In particular, the possibility of haematoma expansion is greatly increased when the haematoma is connected with SDH. The potential mechanisms might be an effect of local pressure around the haemorrhage in cases of PIH. Traumatic haematoma growth often occurs during the first hours after trauma and has been attributed to the continued bleeding of microvessels that were fractured at the time of the primary injury[18]. Patients with subdural haemorrhage are known to be associated with a more severe presentation and a worse clinical outcome. The pressure around the haematoma decreases as intracranial haematoma in connection with SDH, especially in the early stage, result in the rupture of microvessels around the haematoma and in continuous bleeding.

We provide important novel data showing that compared with SDH, NLR is a more sensitive indicator for predicting for early haematoma growth. A high NLR is reflective of both an elevated innate immune response (more polymorphonuclear leukocytes (PMNs)) and a decreased adaptive immune response (fewer lymphocytes)[19]. Similarly, a growing body of evidence supports the presence of systemic immunosuppression following tICH. The inflammatory response in the hyperacute phase of the disease is not only a nonspecific stress-related reaction but may also play a key role in the development of haematomas[8]. Zhou at al. described the role of inflammation in intracranial haematoma, from the underlying mechanisms to clinical translation[20]. In particular, the secondary damage caused by inflammation results in neurological deterioration in patients with $\mathrm{tICH}$ [21]. Secondary damage is triggered by the presence of intraparenchymal blood, which subsequently activates cytotoxic, excitotoxic, oxidative, and inflammatory pathways[22,23]. The inflammatory response of $\mathrm{tICH}$ is characterized by the rapid activation of resident microglial cells and the subsequent infiltration of circulating inflammatory cells, including 
neutrophils and macrophages[24]. Similarly, in the early stages of tICH, large numbers of inflammatory cells are seen around the haematoma in animal studies[25]. These inflammatory cells release inflammatory cytokines that cause secondary injury around the haematoma, leading to the enlargement of the haematoma. Neutrophils may be the first leukocyte subtype to enter a haemorrhage[24]. When the leukocyte invasion is greater, the degree of damage increases. Thus, the NLR predicts haematoma expansion due to the role of neutrophils in haematoma. This might explain how the NLR may be used as predictor for haematoma growth.

The NLR derived from the white blood cell differential count, a routine laboratory study, is easy to obtain and calculate, easy to integrate into daily practice, and does not add extra costs. Another advantage of the NLR is that it is more objective than other predictors (subarachnoid haemorrhage, SDH, the shape of the haematoma on a head CT, etc). Furthermore, slight changes in a patient's physical condition may not be reflected on head CT, whereas it may be reflected in the NLR, which could lead to changes in treatment. One drawback of the NLR is the average turnaround time for relevant laboratory results in the emergency department, which is between 30 and 40 minutes. In comparison, head CT images are able to be viewed within 10 minutes.

Some limitations of our study should be acknowledged. First, some bias might have been introduced in the patient selection and data collection. Accurately calculating the haematoma volume, particularly for a few small haematomas, is difficult with normal CT plane scanning. Second, inflammatory cells and other indicators examined were just analysed on admission, and the changes in inflammatory indicators over the development of the patient's condition were not tracked.

\section{Conclusions}

Our study reveals the novel and easy-to-use NLR that predicts early intraparenchymal haematoma growth in patients with $\mathrm{tICH}$. The NLR can be easily identified by a routine laboratory study and is highly specific and sensitive for predicting haematoma growth.

\section{Abbreviations}

NLR: neutrophil-to-lymphocyte ratio; tICH: traumatic intraparenchymal haemorrhage; EDH: epidural haematoma; SAH: subarachnoid haemorrhage; SDH: subdural haemorrhage; GCS: Glasgow Coma Scale; TBI: traumatic brain injury; CT: computed tomography; OR: odds ratio; Cl: confidence interval.

\section{Declarations}

\section{- Ethics approval and consent to participate}

This study was approved by the Ethics Committee of the First Affiliated Hospital, Shantou University Medical College.

\section{- Consent for publication}

All the selected patients have signed informed consents

\section{- Availability of data and materials}

The datasets used during the current study are available from the corresponding author on reasonable request. 


\section{- Competing interests}

The authors declare that they have no competing interests.

\section{- Funding}

This study was supported by the National Natural Science Foundation of China (81471622 and 81773976); China Postdoctoral Science Foundation (2018M633091); the Natural Science Foundation of Guangdong Province (2019A1515010649); Medical Scientific Research Foundation of Guangdong Province, China (A2017168); Clinical Improvement Program of Shantou University Medical College (201405); Top-tier University Development Scheme for Research and Control of Infectious Diseases (2015026).

\section{- Authors' contributions}

Study concept and design: Drs. Zhuang, Guo, Sheng, Wang, and Chen. Acquisition of data: all authors. Imaging analysis: Drs. Zhuang, Guo, Wang, and Chen. Statistical analysis: Drs. Zhuang, Guo, Wang, and Chen. Analysis and interpretation of data: all authors. Drafting of the manuscript: Drs. Zhuang, Sheng, Wang, and Chen. Critical revision of the manuscript for important intellectual content: all authors. Obtained funding: Drs. Sheng, Li and Chen. Study supervision: Drs. Zhuang, Guo, Sheng, Wang, and Chen.

\section{- Acknowledgements}

Not applicable

\section{References}

1. Huang AP, Lee CW, Hsieh HJ, Yang CC, Tsai YH, Tsuang FY, et al. Early parenchymal contrast extravasation predicts subsequent hemorrhage progression, clinical deterioration, and need for surgery in patients with traumatic cerebral contusion. J Trauma. 2011;71(6):1593-9.

2. Letourneau-Guillon L, Huynh T, Jakobovic R, Milwid R, Symons SP, Aviv RI. Traumatic intracranial hematomas: prognostic value of contrast extravasation. AJNR Am J Neuroradiol. 2013;34(4):773-9.

3. Van den Berghe G, Schoonheydt K, Becx P, Bruyninckx F, Wouters PJ. Insulin therapy protects the central and peripheral nervous system of intensive care patients. Neurology. 2005;64(8):1348-53.

4. Marshall LF, Marshall SB, Klauber MR, Van Berkum CM, Eisenberg H, Jane JA, et al. The diagnosis of head injury requires a classification based on computed axial tomography. J Neurotrauma. 1992;9(Suppl 1):S287-92.

5. Moppett IK. Traumatic brain injury: assessment, resuscitation and early management. 2007;99(1):18-31.

6. Jennett B, Bond M. Assessment of outcome after severe brain damage. Lancet. 1975;1 (7905):480-4.

7. Laird AM, Miller PR, Kilgo PD, Meredith JW, Chang MC. Relationship of early hyperglycemia to mortality in trauma patients. J Trauma. 2004;56(5):1058-62.

8. Chen W, Yang J, Li B, Peng G, Li T, Li L, Wang S. Neutrophil to Lymphocyte Ratio as a Novel Predictor of Outcome in Patients With Severe Traumatic Brain Injury. J Head Trauma Rehabil. 2018;33(1):E53-9.

9. Zimmerman RD, Maldjian JA, Brun NC, Horvath B, Skolnick BE. Radiologic estimation of hematoma volume in intracerebral hemorrhage trial by CT scan. AJNR Am J Neuroradiol. 2006;27(3):666-70.

10. Allison RZ, Nakagawa K, Hayashi M, Donovan DJ, Koenig MA. Derivation of a Predictive Score for Hemorrhagic Progression of Cerebral Contusions in Moderate and Severe Traumatic Brain Injury. Neurocrit Care. 2017;26(1):806. 
11. White CL, Griffith S, Caron JL. Early progression of traumatic cerebral contusions: characterization and risk factors. J Trauma. 2009;67(3):508-14.

12. Dowlatshahi D, Demchuk AM, Flaherty ML, Ali M, Lyden PL, Smith EE. Defining hematoma expansion in intracerebral hemorrhage: relationship with patient outcomes. Neurology. 2011;76(14):1238-44.

13. Brouwers HB, Greenberg SM. Hematoma expansion following acute intracerebral hemorrhage. Cerebrovasc Dis. 2013;35(3):195-201.

14. Morotti A, Phuah CL, Anderson CD, Jessel MJ, Schwab K, Ayres AM, et al. Leukocyte Count and Intracerebral Hemorrhage Expansion. Stroke. 2016;47(6):1473-8.

15. Juratli TA, Zang B, Litz RJ, Sitoci KH, Aschenbrenner U, Gottschlich B, et al. Early hemorrhagic progression of traumatic brain contusions: frequency, correlation with coagulation disorders, and patient outcome: a prospective study. J Neurotrauma. 2014;31(17):1521-7.

16. Nakae R, Takayama Y, Kuwamoto K, Naoe Y, Sato H, Yokota H. Time Course of Coagulation and Fibrinolytic Parameters in Patients with Traumatic Brain Injury. J Neurotrauma. 2016;33(7):688-95.

17. Li Q, Zhang G, Huang YJ, Dong MX, Lv FJ, Wei X, et al. Blend Sign on Computed Tomography: Novel and Reliable Predictor for Early Hematoma Growth in Patients With Intracerebral Hemorrhage. Stroke. 2015;46(8):211923.

18. Kurland D, Hong C, Aarabi B, Gerzanich V, Simard JM. Hemorrhagic progression of a contusion after traumatic brain injury: a review. J Neurotrauma. 2012;29(1):19-31.

19. Brooks SD, Spears C, Cummings C, VanGilder RL, Stinehart KR, Gutmann L, et al. Admission neutrophillymphocyte ratio predicts 90 day outcome after endovascular stroke therapy. J Neurointerv Surg. 2014;6(8):578-83. 20. Zhou Y, Wang Y, Wang J, Anne SR, Yang QW. Inflammation in intracerebral hemorrhage: from mechanisms to clinical translation. Prog Neurobiol. 2014;115(2):25-44.

21. Babu R, Bagley JH, Di C, Friedman AH, Adamson C. Thrombin and hemin as central factors in the mechanisms of intracerebral hemorrhage-induced secondary brain injury and as potential targets for intervention. Neurosurg Focus. 2012;32(4):E8.

22. Aronowski J, Zhao X. Molecular pathophysiology of cerebral hemorrhage: secondary brain injury. Stroke. 2011;42(6):1781-6.

23. Chen W, Sheng J, Guo J, Peng G, Hong J, Li B, et al. Cytokine cascades induced by mechanical trauma injury alter voltage-gated sodium channel activity in intact cortical neurons. J Neuroinflammation. 2017;14(1):73-83. 24. Wang J. Preclinical and clinical research on inflammation after intracerebral hemorrhage. Prog Neurobiol. 2010;92(4):463-77.

25. Wang J, Dore S. Inflammation after intracerebral hemorrhage. J Cereb Blood Flow Metab. 2007;27(5):894-908.

\section{Tables}

Table 1. Characteristics of Patients in the Development Cohort and Validation Cohort. 


\begin{tabular}{|c|c|c|}
\hline Variables & Development Cohort & Validation Cohort \\
\hline Gender (M/F) & $319 / 93$ & $445 / 146$ \\
\hline Age, years & $49.34 \pm 17.62$ & $47.67 \pm 17.99$ \\
\hline GCS score & $11.49 \pm 3.45$ & $11.51 \pm 3.34$ \\
\hline Baseline CT time, hours & $2.70 \pm 1.73$ & $2.84 \pm 2.21$ \\
\hline Hypertension (\%) & $42(10.9)$ & $63(10.9)$ \\
\hline MAP, mmHg & $102.36 \pm 16.77$ & $98.96 \pm 16.14$ \\
\hline Diabetes (\%) & $19(4.7)$ & $27(4.6)$ \\
\hline Smoking (\%) & $42(10.5)$ & $118(19.97)$ \\
\hline Drink abuse (\%) & $31(7.7)$ & $65(11.3)$ \\
\hline Combined injury (\%) & $150(36.4)$ & $254(43.1)$ \\
\hline Contrecoup injury (\%) & $254(61.7)$ & $365(62.3)$ \\
\hline \multicolumn{3}{|l|}{ Lobe of contusion } \\
\hline Frontal (\%) & $181(43.9)$ & $260(44.1)$ \\
\hline Temporal (\%) & $186(45.1)$ & $252(42.7)$ \\
\hline Parietal (\%) & $15(3.6)$ & $37(6.3)$ \\
\hline Occipital (\%) & $9(2.2)$ & $15(2.5)$ \\
\hline Other (\%) & $21(5.1)$ & $26(4.4)$ \\
\hline Multiple lobe contusion (\%) & $215(52.3)$ & 232(39.26) \\
\hline IVH (\%) & $23(5.6)$ & $41(6.94)$ \\
\hline $\mathrm{SAH}(\%)$ & $323(78.4)$ & $415(70.22)$ \\
\hline $\mathrm{SDH}(\%)$ & $244(59.2)$ & $376(63.7)$ \\
\hline EDH (\%) & $78(18.9)$ & $129(26.90)$ \\
\hline Encephalatrophy (\%) & $23(5.6)$ & $27(4.57)$ \\
\hline Initial haematoma volume, mL & $4.39 \pm 7.69$ & $4.76 \pm 11.03$ \\
\hline Multiple hematomas ( $\geq 3$ hematomas), No. (\%) & $61(14.8)$ & 194(32.8) \\
\hline \multicolumn{3}{|l|}{ Inflammatory index parameters } \\
\hline Leukocyte count, $10^{9} / \mathrm{L}$ & $15.50 \pm 5.30$ & $15.16 \pm 5.72$ \\
\hline Neutrophil count, $10^{9} / \mathrm{L}$ & $13.11 \pm 4.87$ & $12.98 \pm 5.36$ \\
\hline Iumnhervto count $10^{9}$ / & $1.40 \pm 0.91$ & $1.25 \pm 0.76$ \\
\hline & $0.87 \pm 0.43$ & $0.84 \pm 0.52$ \\
\hline Mononuclear cell count, $10^{9} / \mathrm{L}$ & $12.37 \pm 9.81$ & $13.95 \pm 11.19$ \\
\hline NLR & $92(22.3)$ & 122(20.64) \\
\hline
\end{tabular}


Abbreviations: GCS, Glasgow Coma Scale; MAP, mean arterial pressure; IVH, intraventricular haemorrhage; SAH, subarachnoid haemorrhage; $\mathrm{SDH}$, subdural haemorrhage; $\mathrm{EDH}$, extradural haemorrhage; NLR, Neutrophil to Lymphocyte ratio.

Table 2. Univariate Analysis of Predictors for PIH in the Development and Validation Cohort. 


\begin{tabular}{|c|c|c|c|c|c|c|}
\hline \multirow[b]{2}{*}{ Variable } & \multicolumn{3}{|c|}{ Development Cohort $(n=412)$} & \multicolumn{3}{|c|}{ Validation Cohort $(n=591)$} \\
\hline & $\begin{array}{l}\text { No PIH } \\
(n=220)\end{array}$ & $\mathrm{PIH}(\mathrm{n}=192)$ & $p$-value & $\begin{array}{l}\text { No PIH } \\
(n=278)\end{array}$ & $\begin{array}{l}\text { PIH } \\
(n=313)\end{array}$ & $p$-value \\
\hline Gender (M/F) & $\begin{array}{l}174 \\
(79.09 \%)\end{array}$ & $\begin{array}{l}147 \\
\text { (76.56\%) }\end{array}$ & 0.724 & $\begin{array}{l}210 \\
(75.54 \%)\end{array}$ & $\begin{array}{l}235 \\
(75.08 \%)\end{array}$ & 0.020 \\
\hline Age, years & $\begin{array}{l}46.70 \\
( \pm 17.21)\end{array}$ & $\begin{array}{l}52.18 \\
( \pm 17.64)\end{array}$ & 0.002 & $\begin{array}{l}47.59 \\
( \pm 17.85)\end{array}$ & $\begin{array}{l}47.74 \\
( \pm 18.15)\end{array}$ & 0.924 \\
\hline GCS score & $\begin{array}{l}11.83 \\
( \pm 3.36)\end{array}$ & $\begin{array}{l}11.09 \\
( \pm 3.52)\end{array}$ & 0.031 & $\begin{array}{l}12.11 \\
( \pm 3.29)\end{array}$ & $\begin{array}{l}10.98 \\
( \pm 3.30)\end{array}$ & $<0.0001$ \\
\hline Baseline CT time, hours & $\begin{array}{l}2.97 \\
( \pm 1.92)\end{array}$ & $2.40( \pm 1.45)$ & 0.001 & $\begin{array}{l}3.14 \\
( \pm 2.58)\end{array}$ & $\begin{array}{l}2.55 \\
( \pm 1.76)\end{array}$ & 0.593 \\
\hline Hypertension (\%) & $\begin{array}{l}21( \\
9.54 \%)\end{array}$ & $21(10.93 \%)$ & 0.411 & $\begin{array}{l}21( \\
7.55 \%)\end{array}$ & $\begin{array}{l}42 \\
(13.42 \%)\end{array}$ & 0.035 \\
\hline MAP, mmHg & $\begin{array}{l}101.86 \pm \\
16.38\end{array}$ & $\begin{array}{l}103.08 \pm \\
17.39\end{array}$ & 0.596 & $\begin{array}{l}97.29 \pm \\
13.20\end{array}$ & $\begin{array}{l}100.45 \pm \\
18.27\end{array}$ & 0.016 \\
\hline Diabetes (\%) & $\begin{array}{l}11 \\
(5.00 \%)\end{array}$ & $8(4.17 \%)$ & 0.501 & $\begin{array}{l}10 \\
(3.60 \%)\end{array}$ & $\begin{array}{l}17 \\
(5.43 \%)\end{array}$ & 0.479 \\
\hline Smoking (\%) & $\begin{array}{l}21 \\
(9.54 \%)\end{array}$ & $21(10.93 \%)$ & 0.381 & $\begin{array}{l}53 \\
(19.06 \%)\end{array}$ & $\begin{array}{l}65 \\
(20.77 \%)\end{array}$ & 0.873 \\
\hline Drink abuse (\%) & $\begin{array}{l}43 \\
(29.45 \%)\end{array}$ & $33(27.73 \%)$ & 0.485 & $\begin{array}{l}32 \\
(25.81 \%)\end{array}$ & $\begin{array}{l}24 \\
(25.81 \%)\end{array}$ & 0.696 \\
\hline Combined injury (\%) & $\begin{array}{l}21 \\
(15.00 \%)\end{array}$ & $21(18.26 \%)$ & 0.326 & $\begin{array}{l}21 \\
(17.21 \%)\end{array}$ & $\begin{array}{l}14 \\
(15.22 \%)\end{array}$ & 0.779 \\
\hline Lobe of contusion & & & 0.07 & & & 0.099 \\
\hline Frontal (\%) & $\begin{array}{l}96 \\
(43.64 \%)\end{array}$ & $87(45.31 \%)$ & & $\begin{array}{l}115 \\
(41.37 \%)\end{array}$ & $\begin{array}{l}145( \\
46.33 \%)\end{array}$ & \\
\hline Temporal (\%) & $\begin{array}{l}95 \\
(43.18 \%)\end{array}$ & $91(47.40 \%)$ & & $\begin{array}{l}116 \\
(41.73 \%)\end{array}$ & $\begin{array}{l}136 \\
(43.45 \%)\end{array}$ & \\
\hline Parietal (\%) & $9(4.09 \%)$ & $6(3.13 \%)$ & & $\begin{array}{l}25 \\
(8.99 \%)\end{array}$ & $\begin{array}{l}12 \\
(3.83 \%)\end{array}$ & \\
\hline Occipital (\%) & $5(2.27 \%)$ & $4(2.08 \%)$ & & $\begin{array}{l}7( \\
2.52 \%)\end{array}$ & $8(2.56 \%)$ & \\
\hline Other (\%) & $\begin{array}{l}14 \\
(6.36 \%)\end{array}$ & $6(3.13 \%)$ & & $\begin{array}{l}14 \\
(5.04 \%)\end{array}$ & $\begin{array}{l}12 \\
(3.83 \%)\end{array}$ & \\
\hline Multiple lobe contusion (\%) & $\begin{array}{l}113 \\
(51.36 \%)\end{array}$ & $\begin{array}{l}102 \\
(53.13 \%)\end{array}$ & & $\begin{array}{l}89 \\
(32.01 \%)\end{array}$ & $\begin{array}{l}232 \\
(74.12 \%)\end{array}$ & \\
\hline IVH (\%) & $\begin{array}{l}14 \\
(6.36 \%)\end{array}$ & $9(4.69 \%)$ & 0.356 & $\begin{array}{l}16( \\
5.76 \%)\end{array}$ & $\begin{array}{l}25( \\
7.99 \%)\end{array}$ & 0.496 \\
\hline SAH (\%) & $\begin{array}{l}161 \\
(73.18 \%)\end{array}$ & $\begin{array}{l}162 \\
(84.38 \%)\end{array}$ & 0.006 & $\begin{array}{l}168( \\
60.43 \%)\end{array}$ & $\begin{array}{l}247 \\
(78.91 \%)\end{array}$ & $<0.0001$ \\
\hline SDH (\%) & $\begin{array}{l}108 \\
(49.09 \%)\end{array}$ & $136(70.83 \%)$ & $<0.0001$ & $\begin{array}{l}128( \\
46.04 \%)\end{array}$ & $\begin{array}{l}248( \\
79.23 \%)\end{array}$ & $<0.0001$ \\
\hline
\end{tabular}




\begin{tabular}{|c|c|c|c|c|c|c|}
\hline EDH (\%) & $\begin{array}{l}43( \\
19.55 \%)\end{array}$ & $35(18.23 \%)$ & 0.801 & $\begin{array}{l}50( \\
17.99 \%)\end{array}$ & $\begin{array}{l}79( \\
25.24 \%)\end{array}$ & 0.086 \\
\hline Encephalatrophy (\%) & $\begin{array}{l}11 \\
(5.00 \%)\end{array}$ & $12(6.25 \%)$ & 0.461 & $\begin{array}{l}13 \\
(4.68 \%)\end{array}$ & $\begin{array}{l}14 \\
(4.47 \%)\end{array}$ & 0.857 \\
\hline Initial haematoma volume, $\mathrm{mL}$ & $\begin{array}{l}3.01 \pm \\
6.36\end{array}$ & $6.27 \pm 8.84$ & $<0.0001$ & $\begin{array}{l}3.58 \pm \\
12.31\end{array}$ & $\begin{array}{l}5.84 \pm \\
9.62\end{array}$ & 0.021 \\
\hline $\begin{array}{l}\text { Multiple hematomas ( } \geq 3 \\
\text { hematomas), No. (\%) }\end{array}$ & $\begin{array}{l}97 \\
(44.09 \%)\end{array}$ & $\begin{array}{l}102 \\
(53.13 \%)\end{array}$ & 0.012 & $\begin{array}{l}52 \\
(18.71 \%)\end{array}$ & $\begin{array}{l}142 \\
(45.37 \%)\end{array}$ & $<0.0001$ \\
\hline Leukocyte count, $10^{9} / \mathrm{L}$ & $\begin{array}{l}15.08 \pm \\
5.67\end{array}$ & $15.97 \pm 4.80$ & 0.085 & $\begin{array}{l}13.52 \pm \\
5.25\end{array}$ & $\begin{array}{l}16.62 \pm \\
5.74\end{array}$ & $<0.0001$ \\
\hline Neutrophil count, $10^{9} / \mathrm{L}$ & $\begin{array}{l}12.26 \pm \\
5.05\end{array}$ & $14.09 \pm 4.46$ & $<0.0001$ & $\begin{array}{l}11.06 \pm \\
4.91\end{array}$ & $\begin{array}{l}14.68 \pm \\
5.18\end{array}$ & $<0.0001$ \\
\hline \multirow{2}{*}{$\begin{array}{l}\text { Mononuclear cell count, } 10^{9} / \mathrm{L} \\
\text { Lymphocyte count } 10^{9} / \mathrm{L}\end{array}$} & $\begin{array}{l}0.88 \pm \\
0.46\end{array}$ & & 0.692 & $\begin{array}{l}0.78 \pm \\
0.50\end{array}$ & $\begin{array}{l}0.89 \pm \\
0.54\end{array}$ & 0.013 \\
\hline & $\begin{array}{l}1.81 \pm \\
1.04\end{array}$ & $0.93 \pm 0.37$ & $<0.0001$ & $\begin{array}{l}1.60 \pm \\
0.89\end{array}$ & $\begin{array}{l}0.93 \pm \\
0.44\end{array}$ & $<0.0001$ \\
\hline NLR & $\begin{array}{l}7.83 \pm \\
3.51\end{array}$ & $\begin{array}{l}17.57 \pm \\
11.92\end{array}$ & $<0.0001$ & $\begin{array}{l}8.48 \pm \\
5.07\end{array}$ & $\begin{array}{l}18.81 \pm \\
12.79\end{array}$ & $<0.0001$ \\
\hline $\begin{array}{l}\text { Surgery for clearing intracranial } \\
\text { hematoma, No. (\%) }\end{array}$ & $\begin{array}{l}23 \\
(10.45 \%)\end{array}$ & $69(53.49 \%)$ & $<0.0001$ & $\begin{array}{l}25 \\
(8.99 \%)\end{array}$ & $\begin{array}{l}97 \\
(30.99 \%)\end{array}$ & $<0.0001$ \\
\hline
\end{tabular}

Abbreviations: GCS, Glasgow Coma Scale; MAP, mean arterial pressure; IVH, intraventricular haemorrhage; SAH, subarachnoid haemorrhage; SDH, subdural haemorrhage; EDH, extradural haemorrhage; NLR, Neutrophil to Lymphocyte ratio.

Table 3. Multivariable Analysis of the NLR for PIH in Development, Validation and Total Cohort.

\begin{tabular}{|c|c|c|c|c|c|c|}
\hline & Development co & & Validation Cohort & & Total Cohort & \\
\hline Factors & OR $(95 \% \mathrm{Cl})$ & $p$-value & OR $(95 \% \mathrm{Cl})$ & $p$-value & OR $(95 \% \mathrm{Cl})$ & $\begin{array}{l}p- \\
\text { value }\end{array}$ \\
\hline SDH & $\begin{array}{l}5.20(2.65 \\
10.21)\end{array}$ & $<0.0001$ & $\begin{array}{l}5.34 \\
(2.67,10.62)\end{array}$ & $<0.0001$ & $\begin{array}{l}3.30(1.97 \\
5.53)\end{array}$ & $<0.001$ \\
\hline$\geq 3$ hematomas & $2.50(1.32,4.72)$ & 0.005 & $3.36(1.87,6.03)$ & $<0.0001$ & $\begin{array}{l}2.28(0.64 \\
2.72)\end{array}$ & $<0.001$ \\
\hline $\begin{array}{l}\text { Lymphocyte } \\
\text { count }\end{array}$ & $0.45(0.23,088)$ & 0.020 & $0.47(0.25,092)$ & 0.035 & $0.42(0.24,0.74)$ & 0.003 \\
\hline NLR & $1.25(1.15,1.37)$ & $<0.0001$ & $1.34(1.24,1.44)$ & $<0.0001$ & $\begin{array}{l}1.74(0.88 \\
3.49)\end{array}$ & $<0.001$ \\
\hline
\end{tabular}

Abbreviations: SDH, subdupment haemorrhage; NLR, Neutrophil to Lymphocyte ratio.

Table 4. ROC Analysis of NLR Model and Multifactor Model for Predicting PIH. 


\begin{tabular}{|c|c|c|c|c|c|c|c|c|}
\hline \multirow[b]{2}{*}{ Model } & \multicolumn{4}{|c|}{ Development Cohort } & \multicolumn{4}{|c|}{ Validation Cohort } \\
\hline & Sensitivity & Specificity & $\begin{array}{l}\text { AUC } \\
(95 \% \mathrm{Cl})\end{array}$ & $\begin{array}{l}P \\
\text { value }\end{array}$ & Sensitivity & Specificity & $\begin{array}{l}\text { AUC } \\
(95 \% \mathrm{Cl})\end{array}$ & $\begin{array}{l}P \\
\text { value }\end{array}$ \\
\hline $\begin{array}{l}\text { Multifactor } \\
\text { model }\end{array}$ & 0.71 & 0.69 & $\begin{array}{l}0.74 \\
(0.68 \\
0.79)\end{array}$ & & 0.61 & 0.81 & $\begin{array}{l}0.77 \\
(0.73,0.81)\end{array}$ & \\
\hline NLR & 0.81 & 0.87 & $\begin{array}{l}0.91 \\
(0.88, \\
0.94)\end{array}$ & $<0.001$ & 0.85 & 0.76 & $\begin{array}{l}0.87 \\
(0.84,0.90)\end{array}$ & 0.001 \\
\hline
\end{tabular}

Abbreviations: NLR, Neutrophil to Lymphocyte ratio.

Table 5. Univariate analysis of predictors for surgical intervention 


\begin{tabular}{|c|c|c|c|}
\hline \multirow{2}{*}{ Variables } & \multicolumn{2}{|c|}{ surgical intervention } & \multirow{2}{*}{$P$-value } \\
\hline & YES & NO & \\
\hline Gender (M/F) & $127 / 39$ & $255 / 84$ & 0.421 \\
\hline Age, years & $49.3 \pm 17.6$ & $49.5 \pm 18.3$ & 0.930 \\
\hline GCS score & $10.36 \pm 3.31$ & $11.35 \pm 3.37$ & 0.002 \\
\hline Baseline CT time, hours & $2.64 \pm 1.75$ & $2.58 \pm 1.64$ & 0.685 \\
\hline Hypertension (\%) & $23(13.9)$ & $40(11.8)$ & 0.292 \\
\hline MAP, mmHg & $102.8 \pm 23.4$ & $98.0 \pm 21.2$ & 0.021 \\
\hline Diabetes (\%) & $11(6.6)$ & $14(4.1)$ & 0.155 \\
\hline Smoking (\%) & 28 (16.9) & $58(17.1)$ & 0.668 \\
\hline Drink abuse (\%) & $16(9.6)$ & $32(9.4)$ & 0.504 \\
\hline Combined injury (\%) & $72(43.4)$ & $138(40.7)$ & 0.317 \\
\hline Contrecoup injury (\%) & $113(68.1)$ & $215(63.4)$ & 0.232 \\
\hline Lobe of contusion & & & 0.599 \\
\hline Frontal (\%) & $69(41.6)$ & $165(48.7)$ & \\
\hline Temporal (\%) & $82(49.4)$ & $145(42.8)$ & \\
\hline Parietal (\%) & $7(4.2)$ & $11(3.2)$ & \\
\hline Occipital (\%) & $3(1.8)$ & $8(2.4)$ & \\
\hline Other (\%) & $5(3.0)$ & $10(2.9)$ & \\
\hline IVH (\%) & $15(9.0)$ & $19(5.6)$ & 0.351 \\
\hline SAH (\%) & $150(90.4)$ & $259(76.4)$ & $<0.001$ \\
\hline $\mathrm{SDH}(\%)$ & $136(81.9)$ & $248(73.2)$ & 0.019 \\
\hline EDH (\%) & $52(31.3)$ & $62(18.3)$ & 0.004 \\
\hline Encephalatrophy (\%) & $2(1.2)$ & $24(7.1)$ & 0.007 \\
\hline Initial haematoma volume, mL & $9.43 \pm 11.11$ & $4.18 \pm 7.63$ & $<0.001$ \\
\hline NLR & $20.64 \pm 18.07$ & $17.21 \pm 8.28$ & 0.004 \\
\hline
\end{tabular}

Abbreviations: GCS, Glasgow Coma Scale; MAP, mean arterial pressure; IVH, intraventricular haemorrhage; SAH, subarachnoid haemorrhage; $\mathrm{SDH}$, subdural haemorrhage; EDH, extradural haemorrhage; NLR, Neutrophil to Lymphocyte ratio.

Table 6. Multivariate logistic regression of predictors for surgical intervention 


\begin{tabular}{|llll|}
\hline Factors & OR value & $95 \% \mathrm{Cl}$ & $\begin{array}{l}\boldsymbol{P} \\
\text { value }\end{array}$ \\
\hline GCS score & 0.929 & $0.873-0.988$ & $\mathbf{0 . 0 1 9}$ \\
MAP & 1.010 & $1.001-1.020$ & $\mathbf{0 . 0 3 8}$ \\
initial haematoma volume & 1.064 & $1.035-1.093$ & $<0.001$ \\
NLR & 1.064 & $1.035-1.093$ & $\mathbf{0 . 0 2 3}$ \\
\hline
\end{tabular}

Abbreviations: GCS, Glasgow Coma Scale; MAP, mean arterial pressure; NLR, Neutrophil to Lymphocyte ratio.

\section{Figures}

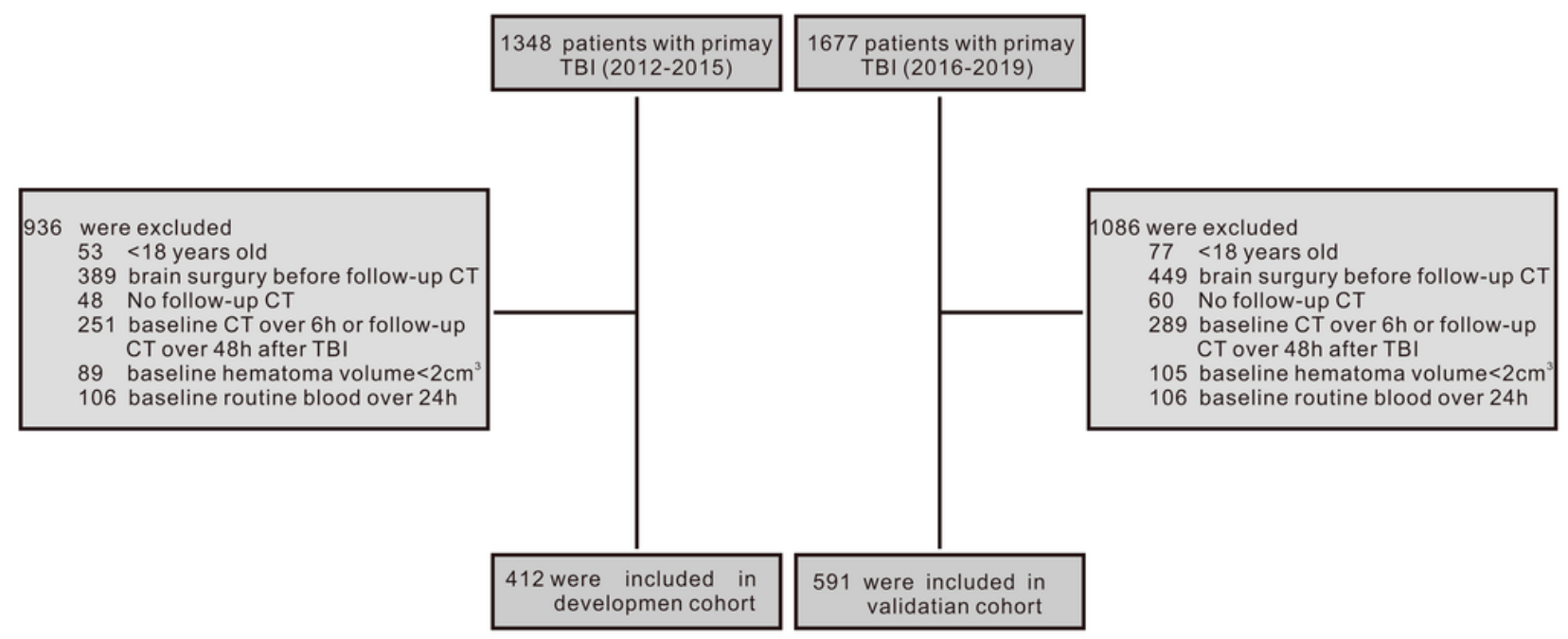

Figure 1

Cohort Selection Flowchart. Inclusion and exclusion flowchart for the retrospective development cohort (between Jan 1, 2012, and Dec 31, 2015, left panel) and prospective validation cohort (between Jan 1, 2016, and April 31, 2019, right panel). 

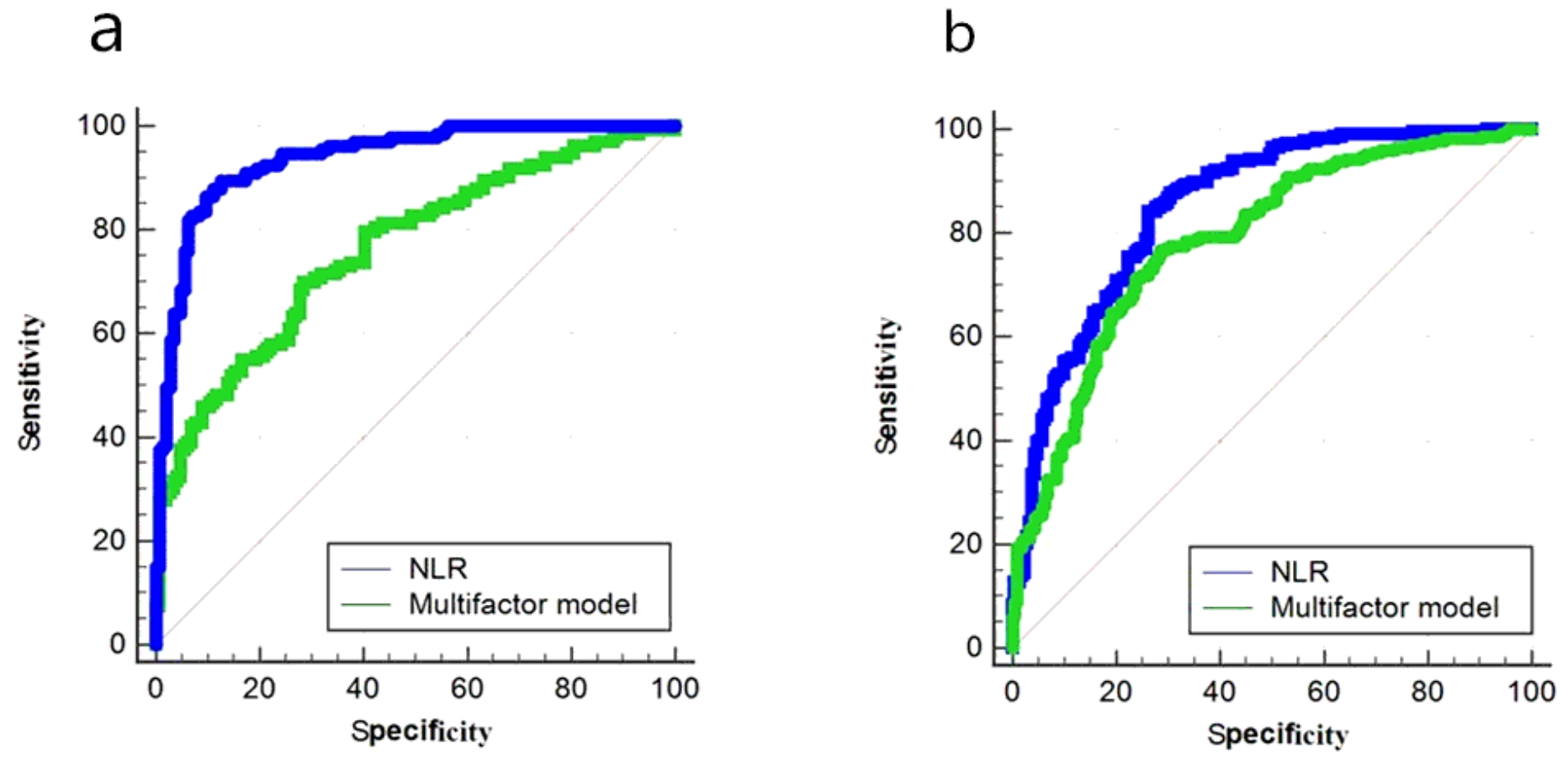

Figure 2

Predictive performance of the single-factor model of the NLR vs. multifactor model in the retrospective cohort and validation cohort. A. retrospective cohort; B. validation cohort. 